\title{
Health Professions Students' Ways of Knowing and Social Orientation in Relationship to Poverty Beliefs
}

\author{
Susan Stewart Bray, Marlene Schommer-Aikins \\ Wichita State University, Wichita, USA
}

\begin{abstract}
The purpose of this study was to examine health professions students' beliefs about the causes of poverty and to identify individual characteristics that may contribute to these beliefs. Health professions students $(n=268)$ and professional school counselors $(n=605)$ completed assessments which assessed three variables: (a) poverty attributes (internal or person's fault and external society's fault); (b) ways of knowing (connected knowing, i.e., empathic and separate knowing, i.e., devil's advocate); and (c) cultural values of group identity, i.e., individualism and, collectivism and power distance, i.e., verticalism and horizontalism. Analyses revealed that the health professions students weighted the internal and external causes of poverty equally, whereas, the school counselors weighted the external causes significantly higher than the internal causes. Regression with both groups of participants combined indicated that those with higher verticalism and lower income, were more likely to blame the person, while those having a multicultural course and higher connected knowing where less likely to blame the person. Those participants with higher separate knowing and verticalism were more likely to blame society.
\end{abstract}

Keywords: poverty, ways of knowing, social orientation, group identity

The official poverty rate in the United States has remained stable for the past four years and for 2014 was 14.8\% with an estimated 46.7 million citizens living in poverty (DeNavas-Walt \& Proctor, 2015). Yet, the declining index of income equality demonstrates the gap between the rich and the poor has continued to widen. Median income remained stable from 2013 to 2014, however in real terms household income has declined 6.5\% since 2007, the year before the most recent recession.

Lott (2002) described the majority culture response to the poor as one of cognitive and behavioral distancing. She defined distancing as "separation, exclusion, devaluation, discounting, and designation of other" (p. 100) by individuals and society. For the poor, barriers are experienced through lack of access to adequate resources such as food, shelter, safety, and health care (Lott, 2012).

The lack of adequate access to health care creates health disparities (Smith-Campbell, 2005). Lott (2002) stated those living in poverty have less access to health promotion literature, lower access to high quality care resources, and face discrimination from health care workers. The health disparities in the United States have led to increased infant mortality, higher rates of obesity, and higher death rates among the poor (Smith-Campbell, 2005).

Susan Stewart Bray, Ph.D., Assistant Professor of Counseling, Counseling Educational Leadership Educational and School Psychology Department, Wichita State University.

Marlene Schommer-Aikins, Ph.D., Professor of Education Psychology, Counseling Educational Leadership Educational and School Psychology Department, Wichita State University. 
Sociologists advanced various philosophical belief systems to explain how attributions are made concerning the causes of poverty in the United States. The two attributional theories most often cited are: (a) poverty is caused by factors external to the person, such as structural factors in society; or (b) poverty is caused internal characteristics of the person or by individual qualities of the person such as laziness (Hunt, 1996; 2000).

External or societal structural factors in society include economic conditions, bad luck, racism, oppression, gender bias, and welfare policies that support the existence of poverty. The internal factors or individualistic explanation theory for poverty taps into a deeply held belief within U.S. society that each person is responsible for his or her place in the social system and that capitalism provides ample opportunities to all who are willing to work hard (Sennett \& Cobb, 1972; Smith \& Stone, 1989).

Researchers have also examined undergraduate students attributions for poverty (Cozzarelli, Tagler, \& Wilkinson, 2002; Cozzarelli, Wilkinson, \& Tagler, 2001; Tagler \& Cozzarelli, 2013). In studies of the general undergraduate population, researchers have found undergraduate students more strongly attribute poverty to the internal characteristics of the person. There is a paucity of research concerning poverty attributions among undergraduate students who are pursuing degrees in the health professions (Smith-Campbell, 2005). Due to the numbers of persons living in poverty, the National Center for Health Statistics (U. S. Department of Education, 2013) has called for those in health professions to develop understandings of the barriers and frustrations experienced by those living in poverty. Those working in the health professions who do receive education regarding the causes of poverty generally do so from simulation exercises (Jarrell, Ozmy, Gallahger, Corrall, \& Hagler, 2014).

In the current study, the authors explored the following questions: Is there a difference between health professions students, who receive limited formal training in multiculturalism and diversity, school counselors whose training programs and professional development emphasizes sensitivity to multiculturalism and diversity? If differences exist between the groups, can individual characteristics such epistemological beliefs (endorsement of separate or connected knowing), the participants' beliefs regarding social power (horizontal or vertical), demographic differences, or multicultural coursework account for the differences?

In the next section, the authors develop a theoretical frame for the concepts of separate and connected knowing, individualism and collectivism, and social relationship hierarchies, concepts that may explain differences in poverty beliefs. In addition, the authors discuss the prior research regarding undergraduate beliefs about the causes of poverty.

\section{Theoretical Frame}

\section{Separate and Connected Knowing}

Belenky, Clinchy, Goldberger, and Tarule (1986) explicated the philosophy of separate and connected knowing. The constructs of separate and connected knowing were an extension of earlier research related to epistemological beliefs, which are beliefs about the nature of knowledge and learning. Perry (1968) began the study of personal epistemology through research with Harvard undergraduates. Perry discovered participants' personal epistemology developed from a belief that knowledge is handed down by authority, to a belief that knowledge is tentative and gathered over time through reason and empirical investigation (Schommer-Aikins \& Easter, 2006). However, other researchers felt Perry's work did not fully explain the development of epistemological beliefs and conducted further research to advance understanding (Belenky et al., 1986; Schommer-Aikins, 2004; Schommer-Aikins \& Easter, 2006, 2009). 
Belenky et al. (1986) studied the perspective of women on the nature of knowledge, truth, and authority. The researchers discovered that for women, the appreciation of another's viewpoint requires relationship and parity between the self and the object, while knowledge implies a detachment and distance from the object. The participants in Belenky et al.'s study came to know or understand information in different ways. For some women, they saw themselves as simply receivers of knowledge. However, as the women matured their thinking and gaining of knowledge become more active and co-constructed. The two approaches the women used for thinking were termed ways of knowing and distinguished by the terms separate knowing and connected knowing. Separate and connected knowing are the constructs of interest in this study.

Connected knowers want to understand another person's perspective before making a decision about accepting the information. For connected knowers, reliable knowledge derives from experience and relationships. Access to the knowledge and understanding of the other person is gained through empathy with the other person's viewpoint and by temporarily taking his or her perspective (Belenky et al., 1986).

Separate knowers use judgment to evaluate the other person's perspective. For separate knowers the method of evaluation and understanding is through the use of impersonal rules to put a new idea on trial and searching for the flaw in the ideas argument or position (Belenky et al., 1986). Separate knowers exclude emotion and emphasize the suppression of personal beliefs to evaluate ideas, and even believe anyone, including his or her self may be wrong. Separate knowers have been called players of devil's advocate and take on an opposing position to a new idea while they weigh, doubt, question, and evaluate. Separate knowers use evidence to understand the position of the other person (Schommer-Aikins, 2004).

\section{Individualism and Collectivism}

Triandis and Gelfand (1998) delineated the constructs of individualism and collectivism by the attributes of: (a) the definition of the self; (b) the place of personal goals; (c) the emphasis on communal relationships; and (d) the importance of social norms and social attitudes. Individualism places emphasis on self-reliance, competition, and emotional distance from in-groups. Collectivism emphasizes interdependence, family integrity, and sociability.

In collectivist cultures, individuals have fewer in-groups, and the highest emphasis is placed on cooperation with the group, relationships, and growing intimate connections (Triandis, Bontempo, Villareal, Asai, \& Lucca, 1988). The social norms in a collectivistic culture are clear, and unquestioned, and the sanctions for violating cultural norms are high. Individual goals are subordinated to the goals of the group (Triandis et al., 1988; Triandis \& Gelfand, 1998; Triandis, McCusker, \& Hui, 1990).

Individualistic cultures have more in-groups such as family, friends, coworkers, club membership, etc., but the attachment to these in-groups is less intense (Trandis et al., 1988). Membership in in-groups tends more toward the temporary and voluntary in individualistic cultures, and individuals are more task-oriented and less relationship focused, but are good at meeting people and forming new groups. Individuals in individualistic cultures place importance on personal goals rather than on group goals.

\section{Horizontal and Vertical Social Relationships}

Triandis and Gelfand (1998) contend that a person's emphasis on power and authority influences his or her view of relationships. Those who emphasize equality and less power differential among people endorse a horizontal social orientation. Those who emphasize hierarchical relationships or a greater power differential among people endorse a vertical social orientation. Individuals who embrace a horizontal pattern of social 
relationships believe that "one self is more or less like every other self" while individuals who endorse vertical patterns see "one self as different from other selves" (Triandis \& Gelfand, 1998, p. 119).

Schommer-Aikins and Easter (2014) conducted a study in which they examined separate and connected knowing in relation to cultural values, and found when people had their in-group in mind their connected knowing was significantly higher than their separate knowing. Yet, when people had an out-group in mind their connected knowing scores dropped to an equivalent level with their separate knowing scores. When Schommer-Aikins and Easter examined the role of cultural values in this phenomenon, they found this drop in connected knowing was evident for all people except those with a strong horizontal social orientation.

\section{Undergraduate Students Attributions about Poverty}

Based on the reviewed research, ways of knowing and social orientation may play a role in how undergraduate health profession students attribute the causes of poverty. Beliefs about the causes of poverty, whether internal or external to the person, likely play a role in the effectiveness of future health professions students' work with clients who live in poverty. In this study, the constructs of beliefs about the causes of poverty separate and connected knowing, and vertical and horizontal social relationship orientation was examined.

The authors of the current study previously examined attributions for poverty, epistemological beliefs, and social relational views in a population of currently practicing school counselors (Bray \& Schommer-Aikins, 2015). The researchers found a relationship among school counselor's endorsement of a vertical hierarchical social structure, the use of separate knowing, less multicultural training, and the endorsement of the idea the internal characteristics of the person cause poverty. Schommer-Aikins and Easter's (2014) previous research has explored the relationship between ways of knowing and social orientation and the current research extends the exploration of this work into a population of health professions students. Health profession student receive no specific education in multiculturalism and diversity, however, the student's future work will likely serve the poor.

The exploration of the beliefs of undergraduates regarding the causes of poverty as related to epistemological beliefs, individualism and collectivism, and social hierarchies remains largely unexplored. In the following section, the authors describe the current study briefly, and provide information regarding the methodology employed in the current study and the results of analysis are included.

\section{Current Study}

Health profession undergraduates were chosen as participants in this study as they are very likely to have contact with clients living in poverty. Yang, Woomer, Agbemnu, and Williams (2014) called for increasing students' empathy and understanding of persons living in poverty. Smith-Campbell (2005) stated health professions students require cultural competence for working with poor clients in order to address health disparities and to improve the quality of services and health outcomes for the poor.

\section{Method}

\section{Participants}

A sample of school counselors who were members of the American School Counseling Association (SC) $(n=605)$ and undergraduate health profession students (HPS) $(n=258)$ participated in this study. The undergraduates were enrolled in a medical terminology class with the majority of students being in lower division college year $($ freshman $=97$; sophomore $=64$; junior $=51$, senior $=49$, unreported $=1$ ). Both groups 
of participants were primarily female. The school counselors had (SC) had 481 females and 124 males. In the health professions student group (HPS) group, 203 students were female and 55 were male. For both groups, the majority of participants were Euro-American (SC: African American = 51; Asian American $=10$; Euro American $=510$; Hawaiian or Pacific Islander $=1$, Other $=16$; and HPS: African American $=15$; Asian American $=33$; Euro American =1,850; Hawaiian or Pacific Islander $=2$, Other $=10$ ).

\section{Measures}

Attitudes Toward Thinking and Learning Survey (ATTLS). Galloti, Clinchy, Ainsworth, Lavin, and Mansfield (1999) created the Attitudes Toward Thinking and Learning Survey (ATTLS) as a measure of an individual's preference for the use of separate knowing (SK) and connected knowing (CK). Participants responded to a 7-point scale from "Strongly disagree" to "Strongly agree". Connected knowing items assess an individual's preference for perspective taking and sample items include: "I can gain insight into the opinions of others through empathy" or "I'm more likely to try to understand someone's position than evaluate it". Separate knowing items assess an individual's preference for taking on a more confrontational role through items such as "I try to point out weakness in other people's thinking to help them clarify their argument" or "I like playing devil's advocate: arguing the opposite of what someone is saying". The ATTLS authors estimated internal reliabilities for the ATTLS scale at 0.83 for the SK scores and at 0.81 for the CK scores (Galotti et al., 1999). Criterion validity for the SK subscale consists of evidence such as participants with higher SK scores supported a greater willingness to argue and see argument as productive indicating a propensity to play devil's advocate Criterion validity for the CK subscale consists of participants with higher CK scores support a preference for working in groups indicating a preference toward understanding. Galotti et al. (1999) reported inter-item correlations of 0.77 for SK and 0.83 for CK.

Attributions for Poverty Questionnaire (APQ). The researchers used Furnham's (1982) adaptation of Feagin's (1972) Attributions for Poverty Questionnaire (APQ) to evaluate participants' beliefs about the causes of poverty. The APQ is a 15-item survey using a 7-point Likert scale for participants to rate their level of agreement with items concerning his or her beliefs about the causes of poverty. In 1972, Feagin determined there are three explanations given for the causes of poverty: (a) poverty is caused by individual characteristics of the person; (b) poverty is caused by societal factors such as government policies and economic forces; and (c) poverty is caused by bad luck or fatalism. Cozzarelli et al. (2001) further investigated the structure of the APQ and provided evidence for a two-factor model of beliefs about poverty. In the two-factor model either poverty is caused by internal characteristics of the person or external forces to the person (societal or cultural factors and bad luck combined). Weiss-Gal, Benyamini, Ginzburg, Savaya, and Peled (2009) provided further evidence for the two-factor model. The two-factor model was used in this study by combining the societal factors and fatalistic factors of the APQ. Principal components factor analysis provided evidence of construct validity for the APQ (Bullock, 1995).

Horizontal and Vertical Individualism and Collectivism Scale (HVICS). Triandis and Gelfand (1998) created a scale that measures the cultural values of horizontal and vertical individualism and collectivism using a 7-point scale ("Strongly disagree" to "Strongly agree"). Ten items measure each cultural value. Triandis and Gelfand used exploratory factor analysis to support predictive validity. The authors found vertical individualists stressed competition, horizontal individualists stressed self-reliance, vertical collectivists stressed authoritarianism and horizontal collectivists stressed interdependence (Triandis \& Gelfand, 1998). 
Discriminatory validity was established using the correlation of items measuring competition, competition, emotional distance from in-groups, family integrity, hedonism, interdependence, self-reliance and sociability (Triandis \& Gelfund, 1998). The construct of interest in this study was the participants' endorsement of either a horizontal or vertical social orientation. The composite scales used in this study were the combined horizontal scale (H) and the combined vertical scale (V). Gouveia, Milfont, Martinez, and Paterna's (2011) calculated Cronbach Alphas for the HVAC scale and results ranged from 0.53 to 0.77 .

Demographic Survey. The researchers created a demographic questionnaire. Participants were asked questions about their gender, age, ethnicity, and race. In addition, participants were asked if they had taken a multicultural course and to provide an estimation of their household income by selecting a category with $\$ 10,000$ dollar increments (e.g., less than $\$ 10,000, \$ 10,000$ to $\$ 19,999, \$ 20,000$ to $\$ 29,999$, etc.).

\section{Procedure}

Participants were recruited via a specific email invitation to the fully online Qualtrics survey program. Upon entry to the survey, respondents first read the informed consent approved by the Institutional Review Board (IRB) for Wichita State University. Participants either accepted or rejected participation in the study. If respondents accepted, they were directed to the survey items. Participants completed ATTLS, APQ, HVICS, and then finally completed the demographic survey. Participants could only access the survey using the unique email invitation sent by the researchers.

\section{Results}

Mean scores were calculated for individual difference and cultural variables. Psychometric analyses included examination of the range, skewness, and inter-item correlations. Descriptive statistics are shown in Table 1. Results indicated that these measures were in the acceptable range.

Table 1

Descriptive Statistics for Major Variables

\begin{tabular}{|c|c|c|c|c|c|}
\hline \multirow{2}{*}{ Key variables } & \multicolumn{2}{|c|}{ School counselors } & \multicolumn{2}{|c|}{ Health profession students } & \multirow{2}{*}{ Cronbach Alpha } \\
\hline & Mean & $S D$ & Mean & $S D$ & \\
\hline Internal cause & 3.15 & 1.00 & 4.09 & 0.86 & 0.82 \\
\hline External cause & 3.91 & 1.22 & 4.13 & 0.98 & 0.77 \\
\hline Connected knowing & 5.92 & 0.62 & 5.31 & 0.84 & 0.79 \\
\hline Separate knowing & 4.31 & 0.79 & 4.45 & 0.80 & 0.68 \\
\hline Verticalism & 3.09 & 0.48 & 3.63 & 0.50 & 0.69 \\
\hline Horizontalism & 3.74 & 0.64 & 4.01 & 0.66 & 0.73 \\
\hline Collectivism & 3.95 & 0.47 & 4.09 & 0.51 & 0.66 \\
\hline Individualism & 3.14 & 0.50 & 3.62 & 0.53 & 0.73 \\
\hline
\end{tabular}

In order to address the question, "Do participants differ in the attitude toward the causes of poverty?" a repeated measures multivariate analysis was conducted. Group identity (SC versus HPS) served as the within group variable and the poverty attributions of Internal causes and External causes of poverty served as the within group variable. There was a significant main effect for poverty attributions: Wilk's Lambda $F(1,826)=$ 69.09, $p<0.001, \eta^{2}=0.08$. Overall poverty external attribution scores were higher than internal attribution scores. There was a significant main effect for respondent type: $F(1,826)=84.36, p<0.001, \eta^{2}=0.09$. Poverty attribution scores were higher for health professions undergraduates compared to school counselors. 
Clarification of these main effects is provided by examining the significant interaction of respondent type $X$ poverty attributions: Wilk's Lambda $F(1,826)=52.32, p<0.001, \eta^{2}=0.06$. Figure 1 shows the interaction effect. Follow-up analyses of within this interaction revealed that undergraduates gave similar (non-significant difference) scores for internal attributions and external attributions. In contrast, counselors gave significantly higher scores to external attributions compared to internal attributions: $F(1,574)=155.05, p$ $<0.001, \eta^{2}=0.21$.

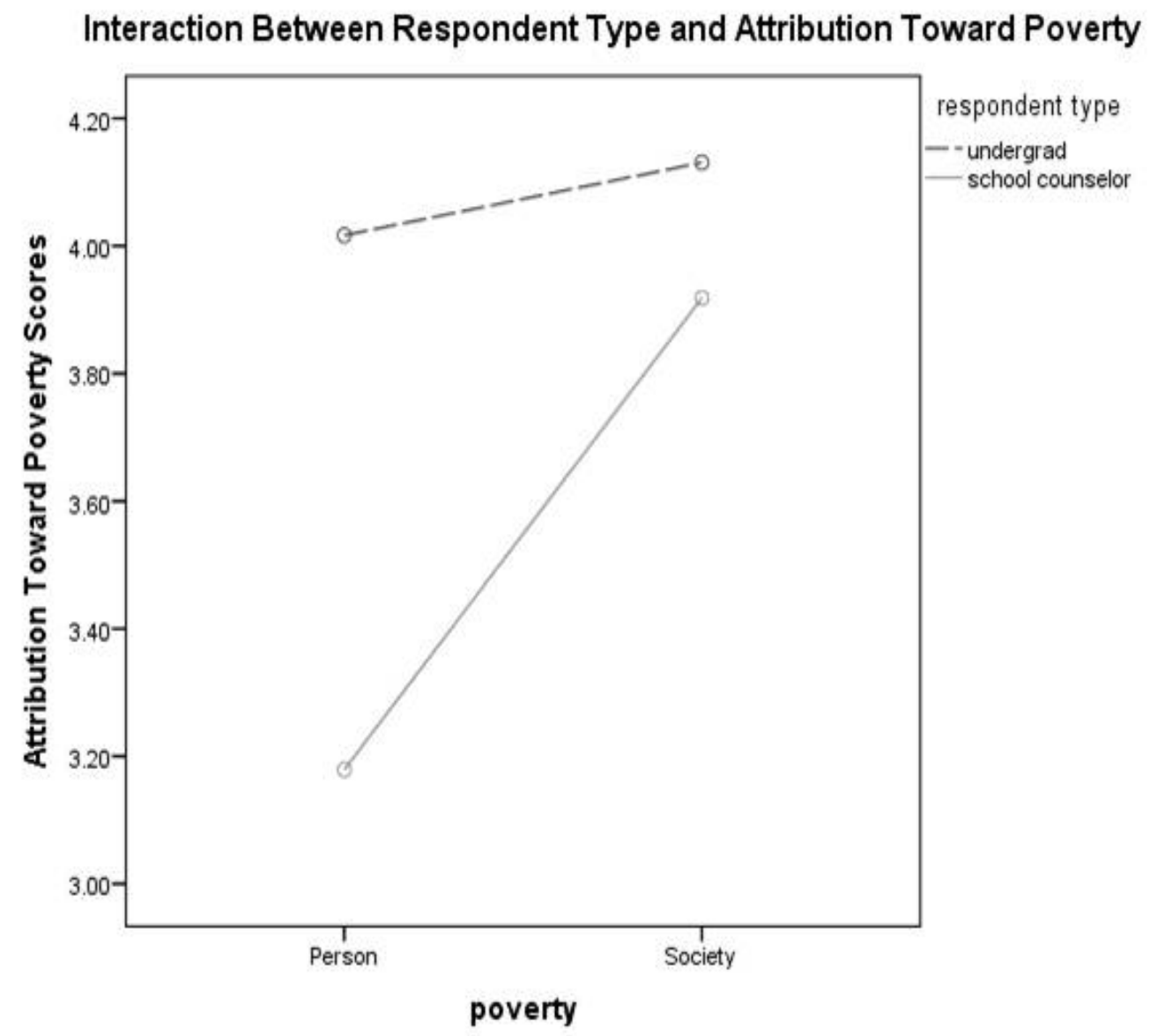

Figure 1. Interaction between respondent type and attributes toward poverty.

In order to address the question: "Can individual differences and multicultural class experience account for group differences?" three regressions analyses were conducted. Each regression was conducted in two steps. In the first step SK, CK, Verticalism, Horizontalism, Collectivist, Individualist, Multicultural course, and Household Income entered into the equation if the constructs were significant at the 0.05 level. In the second step, group identity entered the equation if significant. The notion behind this analysis is that if variables in the first step enter the equation, and subsequently, the difference between SC and HPS is no longer significant, then one could conclude that we have identified factors about the two groups that account for difference in their attitudes toward the causes of poverty.

The criterion variables for each consecutive regression were Internal Cause, External Cause, and Internal Greater Cause (Internal Cause score minus External Cause score). Zero order correlations are shown in Table 2 . 
Table 2

Zero-Order Correlations Among Major Variables

\begin{tabular}{lccccccc}
\hline \multicolumn{1}{c}{ Internal } & External & CK & SK & Vertical & Horizontal & Collective \\
\hline Internal & & & & & & & \\
External & 0.26 & & & & & & \\
CK & -0.20 & 0.03 & & & & & \\
SK & 0.10 & 0.16 & 0.19 & & & & \\
Vertical & 0.34 & 0.13 & -0.13 & 0.21 & & & \\
Horizontal & 0.17 & 0.08 & -0.02 & 0.16 & 0.30 & & \\
Collective & 0.11 & 0.04 & 0.20 & 0.09 & 0.61 & 0.13 & 0.15 \\
Individual & 0.36 & 0.14 & -0.18 & 0.23 & 0.71 & 0.78 & \\
\hline
\end{tabular}

Note. Correlations of 0.20 or higher are significant at the 0.05 level.

When Internal Cause was the criterion variable, five variables in the first step entered the equation. Group differences were no longer significant. These significant predictors included Verticalism $(F(1,729)=94.92, p$ $\left.<0.001, b=0.66, R^{2}=0.12\right)$, Multicultural class $\left(F(1,728)=26.90, p<0.001, b=0.48, R^{2}=0.03\right)$, Household Income $\left(F(1,727)=14.05, p<0.001, b=-0.04, R^{2}=0.02\right), \mathrm{CK}\left(F(1,726)=10.30, p<0.001, b=-0.16, R^{2}=\right.$ $0.01)$, and Individualism $\left(F(1,729)=7.00, p<0.01, b=0.24, R^{2}=0.01\right)$. Participants were more likely to believe that poverty was due to internal (personal) characteristics if they had a propensity to be Verticalists and Individualists, had not taken a multicultural class, had less of propensity for connected knowing and lived in a household with less income.

When External Cause was the criterion variable, two variables in the first step entered the equation. Group differences were no longer significant. These significant predictors included SK $(F(1,745)=21.00, p<0.001$, $\left.b=0.24, R^{2}=0.03\right)$ and Verticalism $\left(F(1,744)=9.16, p<0.01, b=0.23, R^{2}=0.01\right)$. Participants were more likely to believe the poverty is due to external forces when they had a propensity toward separate knowing and were verticalists.

When Internal Greater Attribute was the criterion variable, four variables in the first step entered the equation. Group differences were no longer significant. These significant predictors included Multicultural class $\left(F(1,732)=31.91, p<0.001, b=0.66, R^{2}=0.04\right), \quad \mathrm{CK}\left(F(1,731)=12.82, p<0.001, b=-0.24, R^{2}=\right.$ $0.02)$, Individualism $\left(F(1,730)=7.84, p<0.01, b=0.25, R^{2}=0.01\right)$, and $\operatorname{SK}(F(1,726)=4.19, p<0.05, b=$ $-0.13, R^{2}=0.01$ ). Participants were more likely to believe that poverty was do more to internal (personal) characteristics of poverty compared to external causes when they had not taken a multicultural class, had a lower propensity toward connected knowing and separate knowing, and individualists.

In summary, significant differences between groups (SC versus HPS) were found in beliefs for both Internal and External cause of poverty. The effect size for differences was greatest for belief in Internal causes of poverty. More importantly, group differences were dropped to non-significant values, when individual difference variables entered the equations first. This finding helps pinpoint what aspects of the groups contributed to their differing attitudes toward poverty.

Taken as a whole, having a multicultural class decreased participants' view of Internal causes of poverty. In addition, having stronger propensity to connected knowing, separate knowing, and earning less money contributed to a decrease in the view of Internal causes of poverty. Conversely, having a stronger propensity toward Individualism and Verticalism predicted an increase in the view of Internal causes of poverty. 
In the section following, the authors discuss the findings of the current study. The authors provide a comparison and contrast regarding the current results and results of other studies, placing the current study in context. Finally, limitations and suggestions for future research are provided.

\section{Discussion}

The results of this study provide insight into health profession students' attributions toward poverty. Students' attributions were contrasted with professional counselors' attributions. The initial analysis revealed that students attributed poverty to both internal and external causes at similar levels. Hence, although students appear to acknowledge that societal factors contribute to poverty, they are just as likely to assume that those who are in poverty are lazy and perhaps have loose morals. These results coincide with those of Smith-Campbell (2005) who found health professions students were likely to agree poor patients receive a lower quality of care, but also agree that measures such as a minimal charge for services is needed to prevent abuse of the system by the poor. The health profession's students view contrasts with the school counselors' views. Although counselors acknowledge that those in poverty may contribute to their own plight, society plays a significantly greater role in poverty.

Further analysis attempted to uncover participant characteristics that contribute to the differences between health profession students and professional counselors by conducting a series of regression analyses. When the internal cause (person variable) was the criterion variable, having a propensity to verticalism and having less income increased the likelihood of attributing poverty to person variables. However, participating in a multicultural course and having a stronger propensity toward connected knowing, predicted lower attributions to person variables. The results suggest that educational interventions increasing awareness of cultural competence may be beneficial to health professions students (Smith-Campbell, 2005).

When the external cause was the criterion variable, having a propensity to verticalism and separate knowing increased the likelihood of attributing poverty to societal or external factors. In both regressions, inclusion of participant characteristics eliminated differences between students and counselors. This suggests that these characteristics (rather than the inherent notion that one is a counselor versus one is a student in health professions) are the important contributors to participants' poverty attributions.

A third regression that used the degree of difference between person and society attributions was most revealing of all. Higher scores in the dependent measure indicated that participants put most of the attribution toward the person rather than society. The more participants had a propensity to individualism, the more blame they attributed toward the person. This suggests that participants with a strong value of rugged individualism believe that people are responsible for their own fate. Bullock (2013) identified individualism as one of the core tenets in American Society for explaining socioeconomic differences. This is consistent with prior research, which found substantial correlations between individualism and internal attributions of poverty (Bray \& Schommer-Aikins, 2015; Bullock, 2008).

In contrast, the more participants had a propensity to toward separate knowing and had experienced a multicultural class, the less blame they attributed to the person. This suggests that being a separate knower allows participants to separate themselves from the poverty dilemma people face. They do not fall into the trap of blaming the victim (Lott, 2002). The multicultural class also allows participants to have a more complete understanding of those other than themselves and the situational factors that may contribute to the lives of those less fortunate. Multicultural courses emphasize increasing students' cultural knowledge, cultural awareness, 
and cultural skills (Arredono, 1999; De'Andra, Daniels, \& Heck, 1991; Smith-Campbell, 2005).

Health professionals who serve the poor may be affected by their attributions toward poverty. If they attribute poverty more to the person than society it is possible that they may not serve patients at comparable levels of the middle or upper class patients (Smith-Campbell, 2005). Unconsciously, they may assume that a persons' medical dilemma is due to their lack of morality or self-control. Unconsciously, they respond slower in an emergency room. Unconsciously, they may assume giving medical advice is a waste of time because the poor patient will not following directions diligently.

By identifying individual characteristics that predict attributions toward poverty, these results highlight factors that are amenable to instruction. Providing multicultural education to health professionals can help health providers be aware of society contributions toward poverty. Hence, deleterious assumptions about patients' morals and habits can be changed through education, training, and exposure. College courses can explicitly teach both connected knowing and separate knowing. Through education students begin to understand that deep thinking requires the yin and yang (walk in other shoes and being a devil's advocate) of both ways of knowing. Vacillating between both ways of knowing is mentally challenging. However, the mental effort will help students, soon to be health professionals, have a better understanding of their patients in poverty. It will help them communicate with their patients and ultimately serve their patients equitably.

As in all research, this study has limitations. As the sample of health professions students was taken from one university, it may not be representative of all health professions students. In addition, the school counselors surveyed were all members of the American School Counselor Association, and may not represent the larger community of all school counselors. In addition, the survey was given to both groups in an online format, and the impact of the anonymity of an online survey may have impacted results.

Future research on ways of knowing, social orientations, and attitudes toward poverty with more representative groups is indicated. Further research comparing the current sample to a larger sample of health professions students is indicated.

\section{References}

Arredondo, P. (1999). Multicultural counseling competencies as tools to address oppression and racism. Journal of Counseling and Development, 77, 102-108.

Belenky, M. F., Clinchy, B. M., Goldberger, N. R., \& Tarule, J. M. (1986). Women's ways of knowing. New York: Basic Books.

Bray, S. S., \& Schommer-Aikins, M. (2015). School counselors' ways of knowing and social orientation in relationship to poverty beliefs. Journal of Counseling \& Development, 93, 312-320. doi:10.1002/jcad.12029

Bullock, H. E. (1995). Attributions for poverty: A comparison of middle-class and welfare recipient attitudes (Unpublished doctoral dissertation, University of Rhode Island, Kingston, RI).

Bullock, H. E. (2008). Justifying inequality: A psychology analysis of beliefs about poverty and the poor. In C. Lin \& D. Harris (Eds.), The colors of poverty: Why racial and ethnic disparities exist. New York, NY: Russell Sage.

Bullock, H. E. (2013). Beliefs about poverty, wealth, and social class: Implications for intergroup relations and social policy. In H. E. Bullock (Ed.), Women and poverty: Psychology, public policy, and social justice (pp. 40-69). Hoboken, NJ: John Wiley and Sons.

Cozzarelli, C., Tagler, M. J., \& Wilkinson, A. V. (2002). Do middle-class students perceive poor women differently? Sex Roles, 11/12, 519-526.

Cozzarelli, C., Wilkinson, A. V., \& Tagler, M. J. (2001). Attitudes toward the poor and attributions for poverty. Journal of Social Issues, 57, 207-227.

D’Andrea, M., Daniels, J., \& Heck, R. (1991). Evaluating the impact of multicultural counseling training. Journal of Counseling and Development, 70, 143-150. doi: 10.1002/j.1556-6676.1991.tb0157.x 
DeNavas-Walt, C., \& Proctor, B. D. (2015). U.S. Census Bureau, population reports, P60-243: Income, Poverty, and health insurance coverage in the United States, 2014. Washington, D. C.: U.S. Government Printing Office.

Feagin, J. (1972). Subordinating the poor. Englewood Cliffs, NJ: Prentice Hall.

Furnham, A. (1982). The protestant work ethic and attitudes toward unemployment. Journal of Occupational Psychology, 55, 277-285.

Galotti, K. M., Clincy, B. McV., Ainsworth, K. H., Lavin, B., \& Mansfield, A. F. (1999). A new way of assessing ways of knowing: The Attitudes Toward Thinking and Learning Survey (ATTLS). Sex Roles, 40, 745-765. doi: 10.1023/A:1018860702422

Gouveia, V. V., Milfont, T. L., Martinez, M. C., \& Paterna, C. (2011). Individualism-collectivism as predictors of prejudice toward gypsies in Spain. Interamerican Journal of Psychology, 45, 223-234.

Hunt, M. O. (1996). The individual, society, or both? A comparison of Black, Latino, and White beliefs about the causes of poverty. Social Forces, 75, 293-322. doi:10.2307/2580766

Hunt, M. O. (2000). Status, religion, and the beliefs in a just world: Comparisons of African Americans, Latinos, and Whites. Social Science Quarterly, 81, 325-343.

Jarrell, K., Ozymy, J., Gallagher, J., Corral, C., \& Hagler, A. (2014). Constructing the foundations for compassionate care: How service-learning affects nursing students' attitudes toward the poor. Nurse Education Practice, 14, 299-303. doi:10.1016/nepr.2013.11.004

Lott, B. (2002). Cognitive and behavioral distancing from the poor. American Psychologist, 57, 100-110. doi:10.1037/0003-066x.57.2.100

Lott, B. (2012). The social psychology of class and classism. American Psychologist, 57, 650-658. doi:10.1037/a0029369

Perry, W. G., Jr. (1968). Patterns of development in thought and values of students in a liberal arts college: A validation of a scheme (ERIC Document Reproduction Service No. ED 024315). Cambridge, MA: Bureau of Study Counsel, Harvard University.

Schommer-Aikins, M. (2004). Explaining the epistemological belief system: Introducing the embedded systemic model and coordinated research approach. Educational Psychologist, 39, 19-29. doi:10.1207/s15326985Sep3901_3

Schommer-Aikins, M., \& Easter, M. (2006). Ways of knowing and epistemological beliefs: Combined effect on academic performance. Educational Psychology, 26, 411-423. doi:10.1080/01443410500341304

Schommer-Aikins, M., \& Easter, M. (2009). Ways of knowing and willingness to argue. The Journal of Psychology, 143, 117-132. doi:10.3200/JRLP.143.2.117-132

Schommer-Aikins, M., \& Easter, M. (2014). Cultural values at the individual level and the malleability of ways of knowing. Educational Psychology: An International Journal of Experimental Educational Psychology, 34(2), 171-184.

Sennett, R., \& Cobb, J. (1972). The hidden injuries of class. New York: Alfred A. Knopf.

Smith, K. B., \& Stone, L. H. (1989). Rags, riches, and bootstraps: Beliefs about the causes of wealth and poverty. Sociological Quarterly, 30, 93-107. doi:10.1111/j-1533-8525.1989.tb01513.x

Smith-Campbell, B. (2005). Health professional students' cultural competence and attitudes toward the poor. Journal of Allied Health, 34, 56-61.

Tagler, M. J., \& Cozzarelli, C. (2013). Feelings about the poor and beliefs about the causes of poverty: The role of affective-cognitive consistency in help-giving. Journal of Psychology, 147, 519-539.

Triandis, H. C., Bontempo, R., Villareal, M. J., Asai, M., \& Lucca, N. (1988). Individualism and collectivism: Cross-cultural perspectives on self-ingroup relationships. Journal of Personality and Social Psychology, 54, 323-338.

Triandis, H. C., \& Gelfand, M. J. (1998). Converging measurement of horizontal and vertical individualism and collectivism. Journal of Personality and Social Psychology, 74, 118-128. doi:10.1037/0022-3154.74.1.118

Triandis, H. C., McCusker, C., \& Hui, C. H. (1990). Multimethod probes of individualism and collectivism. Journal of Personality and Social Psychology, 59, 1006-1020. doi:10.1037/0022-3514.59.5.1006

U.S. Department of Education, National Center for Education Statistics, Common Core of Data. (2013). Public Elementary/Secondary School Universe Survey 1999-2000 and 2011-12. Retrieved from http://nces.ed.gov/ccd/pubschuniv.asp

Weiss-Gal, I., Benyamini, Y., Ginzburg, K., Savayd, R., \& Peled, E. (2009). Social workers and service workers attributions for poverty. Social Work, 54, 125-133. doi: 10.1093/sw/54.2.125

Yang, K., Woomer, G. R., Agbemenu, K., \& Williams, L. (2014). Relate better and judge less: Poverty simulation promoting culturally competent care in community health nursing. Nursing Education Practice, 14, 680-685. doi:10.1016/j.nepr.2014.09.001 